\title{
Fatigue characterization of mechanical components in service
}

\author{
G. Fargione, D. Tringale \\ Dipartimento di Ingegneria Industriale e Meccanica, Università degli Studi di Catania, Viale Andrea Doria 6, 95125 Catania \\ E. Guglielmino, G. Risitano \\ Università degli Studi di Messina, Dipartimento di Ingegneria Elettronica, Chimica e Ingegneria Industriale, Contrada Di Dio (S. \\ Agata), 98166 Messina \\ grisitano@unime.it
}

\begin{abstract}
The quickly identify of fatigue limit of a mechanical component with good approximation is currently a significant practical problem not yet resolved in a satisfactory way. Generally, for a mechanical component, the fatigue strength reduction factor $\left(\beta_{i}\right)$ is difficult to evaluate especially when it is in service.

In this paper, the procedures for crack paths individuation and consequently damage evaluation (adopted in laboratory for stressed specimens with planned load histories) are applied to mechanical components, already failed during service. The energy parameters, proposed by the authors for the evaluation of the fatigue behavior of the materials [1-5], are defined on specimens derived from a flange bolts. The flange connecting pipes at high temperature and pressure. Due to the loss of the seal, the bolts have been subjected to a hot flow steam addition to the normal stress.

The numerical analysis coupled experimental analysis (measurement of surface temperature during static and dynamic tests of specimens taken from damaged tie rods), has helped to determine the causes of failure of the tie rods.

The determination of an energy parameter for the evaluation of the damage showed that factors related to the heat release of the material (loaded) may also help to understand the causes of failure of mechanical components.
\end{abstract}

KEYWORDS. Mechanical components in service; RRM; Fatigue.

\section{INTRODUCTION}

$\mathrm{I}$ $\mathrm{n}$ this work it has been applied to mechanical components damaged during the working phase, the procedures of damage assessment which have been already adopted in laboratory on the test specimens stressed with programmed loads history. The energy parameters proposed for years by the authors to estimate the materials fatigue behaviour, have been tested on specimens made out of the bolts of a connection flange of high temperature and head steam pipes which have been subjected not only to the usual proof stress, but also to a steam flux caused by a leak of the seal. The numerical and the following experimental analysis carried out through the measurement of the surface temperature during the static and dynamic tests on the specimens made out of by damaged slings allowed to define the causes for the slings breakage. The determination of a reference energy parameter to evaluate also the damage sustained by the material has highlighted again how the factors linked to the material heat release under stress can help to evaluate also the causes of the failure of the mechanical components. 
Since 1982 the authors have proposed the energy analysis to evaluate the mechanical characteristics of the materials. Risitano and the members of his staff [1-5] have first pointed out how an analysis of the temperature of a stressed specimen (dynamic and also static) is a parameter (the third parameter in association with the stress and the time during the fatigue test) which allows to recognize the birth of irreversible deformations (in general) which generate heat. They have chosen as energy indicator to assess the start of the damage, the surface temperature of the specimen and they have used spread-range instruments (infrared thermographs) to evaluate it on the entire area. They have proposed the use of the temperature integral of the hottest point during the rupture time $\left(\Phi=\int T d N\right)$ as the energy parameter useful for the evaluation of the energy breaking limit $\left(E_{l}\right)$ (the energy which is necessary to break the material through dynamic stresses); carrying out some experiments they have verified in several works that the parameter $\Phi$ is constant for each material (component) as it is constant $E_{l}$, following reliable theories. According to this result it has been proposed a methodology which allows to calculate, using a limited number of specimens (theoretically just one of them), not only the fatigue limit but also the entire fatigue curve. During the last years, according to Risitano and his school experiments, different authors [6-13] have applied and confirmed the validity of this methodology, extending it to other materials different from the steels and for which this methodology was born. Risitano and the members of his staff have applied the methodology to mechanical components characterizing the fatigue of the components themselves [14], to verify the possibility of estimating a material's fatigue limit by studying the surface temperature evolution of a specimen loaded with a static axial force [15-19] and to propose a new linear damage model [20-23]. For years and according with the endless application of this methodology, the temperature has been adopted as a damage or a change index of the characteristics of the material. It has been observed that, being the material or the component equal, the surface temperature trend under the same load is different if the component has been previously damaged or not. Some authors have recently referred to energetic parameters to evaluate the damage. Atzori et al. [24] refers to the heat $Q$ released after the material has been stressed for a certain period of time (number of cycles) and with loads which exceed the fatigue limit. On the contrary Naderi et al. [25] refer to the entropic status of the material and they use the entropy as an energy parameter. It is clear that both [24] and [25] consider as reference parameter entities which are directly connected with Risitano surface temperature because it deals with strong materials with slight volume variations. The surface temperature as the important parameter connected with the stress of the material has been used by Risitano as an indicator of the end of the elastic phase and the beginning of local micro plasticizations in single-axle traction tests. The fatigue failure happens when a stress which causes the beginning of the plasticization is applied in repetitive way. Therefore, the fatigue limit corresponds to the external stress value (macroscopic), able to produce irreversible local deformation, which is determinable by the slope change of the temperature vs strain curve in a static monotonic traction test. It means that the fatigue limit is coincident with the external stress value (load / area) which, during static traction test, causes micro plasticizations inside the material in order to reach local stresses compatible with the beginning of the irreversible deformation phenomena and heat production consequently.

In this work the above mentioned principles have been applied for the assessment of the cause which has caused the breakage of two of the eight tie rods of a measure flange of a steam unit petroleum-processing plant (Fig. 1).

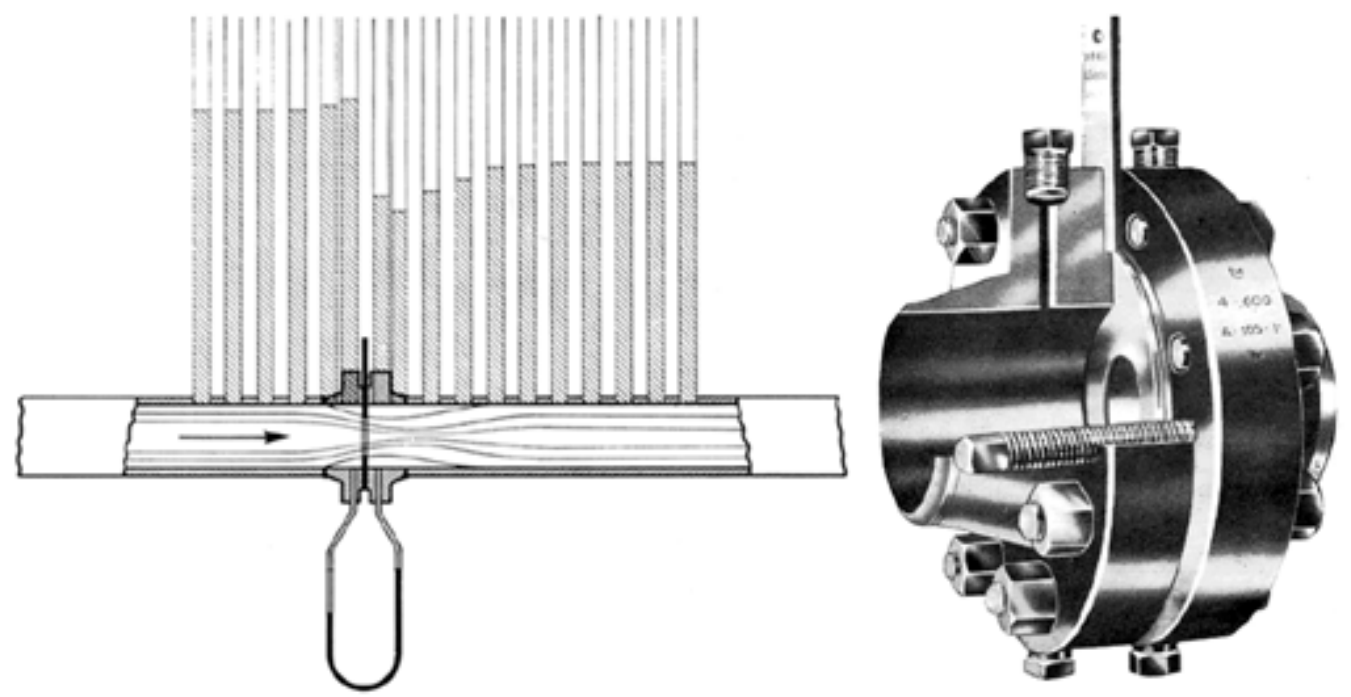

Figure 1: Flange of a steam unit petroleum-processing. 


\section{MATERIALS AND METHODS}

$\mathrm{T}$ he need to know the causes of the breakage of two of the eight tie rods of a measure flange during the maintenance operation, suggested the authors to apply, on a material belonging to damaged or broken elements, the procedures applied in to the lab to evaluate the material fatigue characteristics.

The visual examination of the broken tie rods has revealed some clear-cut breakages, without huge plastic deformations, near the mean line of the tie rods (Fig. 2) and in particularly next to the seal. The integrity (as it seems at a first visual examination) of the residual six tie rods recommends to avoid damaging them, both to support the exercise needs and also to use the first broken one to establish the mechanical characterization of the material. The hypothesis that the leakage of high-temperature $\left(260^{\circ} \mathrm{C}\right)$ and high-pressure steam $(161 \mathrm{ATA})$ just from one side of the flange should have caused the two tie rods failure due to the steam mechanical effect, has persuaded the present authors to characterize the material of the shorn tie rods. Starting from a finite elements analysis which simulate also the steam leakage from the seal, it has been noticed that, in the middle of the tie rod near the seal, the stresses were higher than the usual material strength parameters. The validation of the failure theory has been found examining the conditions of the material of the broken tie rods. The characterization has been achieved with the analysis of the heat releases (thermographic method)of the limited number of the specimens which should be obtained by the two broken tie rods.

The Tab. 1 reports the characteristics of the tie rods which were totally threaded (ISO metric thread with UNI 6610-69 fine pitch), while Tab. 2 reports the specific characteristics. The Tab. 3 reports the steal chemical characteristics.

\begin{tabular}{lll}
\hline Camping Element & Quantity & Identification Mark \\
Tie rods M39x3 & 8 & I3 \\
Screw Material & Regulations & Heat Treatment \\
\hline 40CrMo4 & UNI 5332-64 & Quenching \\
Screw Nut Material & Regulations & Heat Treatment \\
40CrMo4 & UNI 5332-64 & Normalized \\
\hline
\end{tabular}

Table 1: Flange characteristics.

\begin{tabular}{lllll}
\hline Identification Mark & Material & $\begin{array}{l}\text { Used Temperature } \\
{\left[{ }^{\circ} \mathrm{C}\right]}\end{array}$ & $\begin{array}{l}\text { Camping } \\
\text { Element }\end{array}$ & Root Section $\left[\mathrm{mm}^{2}\right]$ \\
I3 & 40CrMo4 & $-10 / 375$ & M39x3 & 980 \\
\hline
\end{tabular}

Table 2: Identification Characteristics

\begin{tabular}{ccccccc}
\hline $\mathrm{C}$ & $\mathrm{Si}$ & $\mathrm{Mn}$ & $\mathrm{P}$ & $\mathrm{S}$ & $\mathrm{Al}$ & $\mathrm{Cr}$ \\
\hline $0.44 \%$ & $0.35 \%$ & $1.00 \%$ & $0.035 \%$ & $0.04 \%$ & $0.02 \%$ & $1.2 \%$ \\
\hline
\end{tabular}

Table 3: 40CrMo4 heat-treated steal chemical characteristics.

For each of the two tie rods slugs (from now on called A and B) it has been created two clepsydra specimens of $5 \times 15 \times 50$ suitable sizes, with a total length of $150 \mathrm{~mm}$, as it is shown in Fig. 3. Therefore there were four tie rods specimens for A and four tie rods specimens for B. 


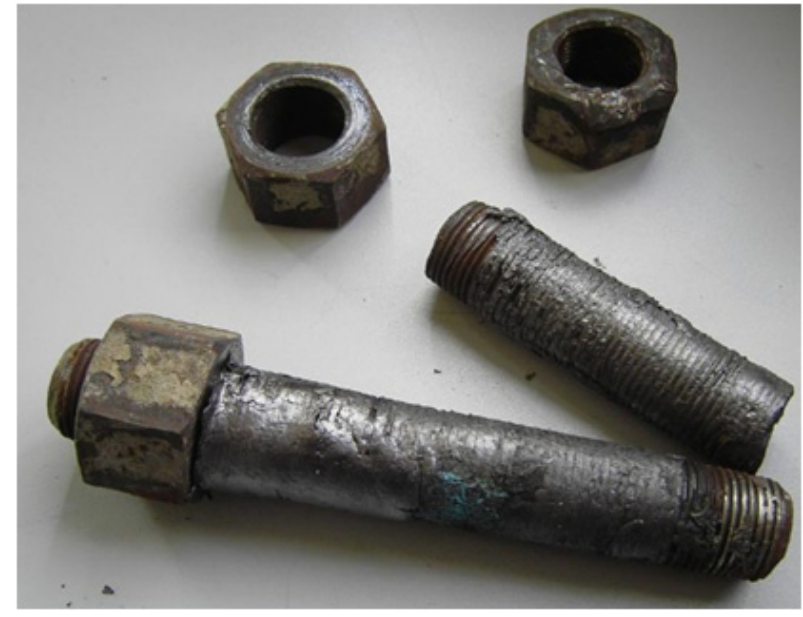

Figure 2: Clear-cut breakages of tie rods.

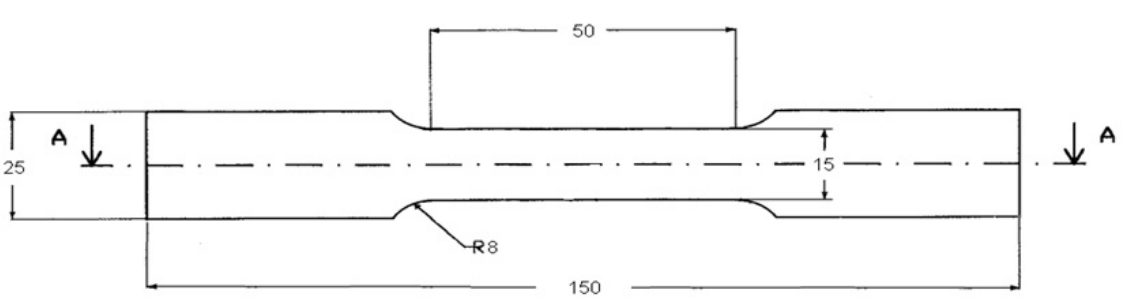

Sez A-A

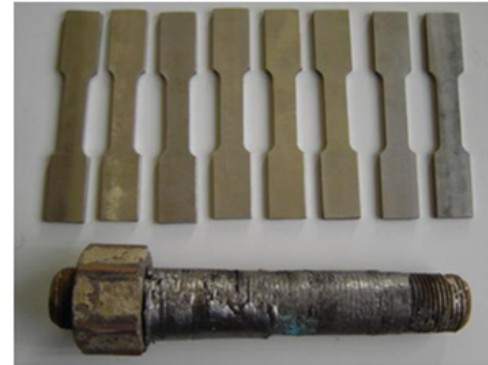

Figure 3: For each of the two tie rods slugs it has been created two clepsydra specimens (measures in $\mathrm{mm}$ ).

The realization of the single specimen has been done using cutting and milling mechanical working as it is indicated in Fig. 3. It has been realized eight specimen but just one of the tie rod A (specimen 1) and one of the tie rod B ( specimen 2) have been used for the execution of the static tests; the other ones have been used for the fatigue tests.

\section{RESULTS}

\section{FE Analysis}

$\mathrm{B}$ efore examining the characterization of the material of the broken tie rods, it has been done a numerical analysis to value the stresses on the same tie rods during a normal work. After the modelling of the flange-tie rods coupling system (Fig. 4), the analysis has been done first using the code $\operatorname{Marc}^{(R)}$ of $M S C^{(R)}$ considering the contact conditions among the different parts ( flange, seal, tie rods, nuts) and it has been pointed out the general stress and deformation states. The Fig. 5.a shows the stress reached by the different parts applying the working loads and the Fig. 5.b shows the tie rod stresses trend.

A second analysis has been done examining the tie rod just with the nuts at the ends: it has applied there the same pressures which they can receive during a normal work. The Fig. 6 shows the model and the corresponding calculated stresses.

Both in the first (complete system) and in the second modelling (pivot and nuts) it has been observed, as expected, that the maximum stresses were near the link to the end nuts and that in the middle section, where the tie rods were broken, the stresses, due to the applied camping values, reached about $220 \mathrm{MPa}$ lower than the material yield load (835 MPa). It can be observed that during the "lighter" second simulation, the deformed stress status was equal to the status obtained using a complex model where the mutual actions among the different connection components (flange, seal, tie rods, nuts) had been considered. Therefore, it has been chosen to use a simple model to simulate the tie rod undergone both the onstream forces and the steam jet caused by the seal leakage. 
The Fig. 7 shows the tie rod middle section stressed with a temperature of $450{ }^{\circ} \mathrm{C}$ and for a length equal to the seal thickness.
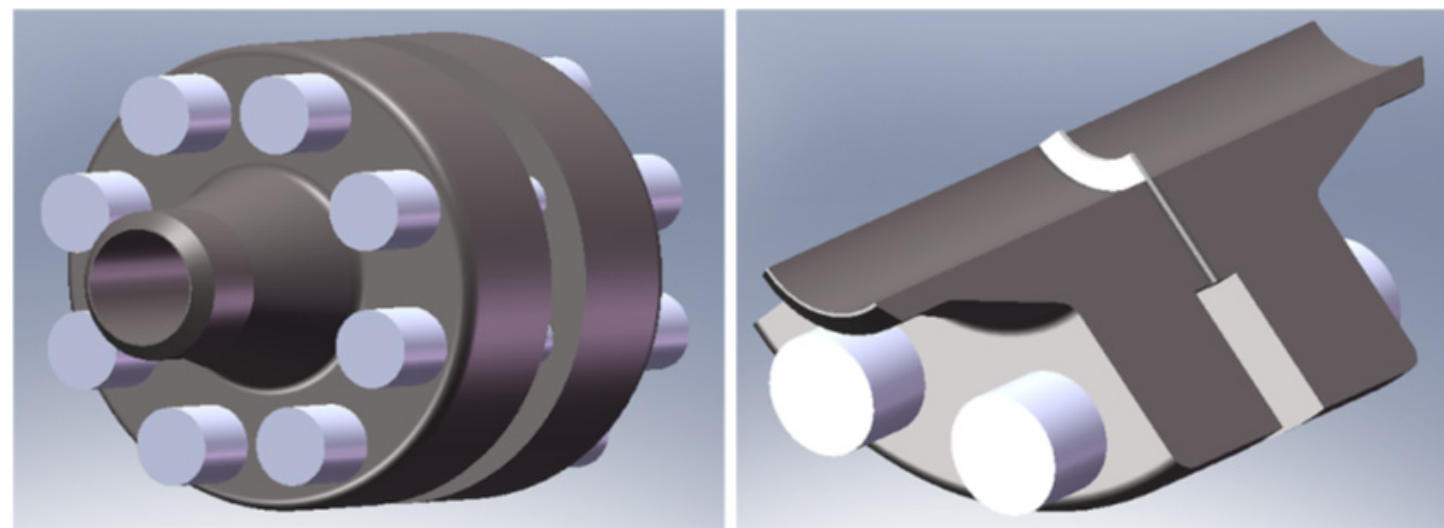

Figure 4: Solidworks model of a part of the flanged coupling.

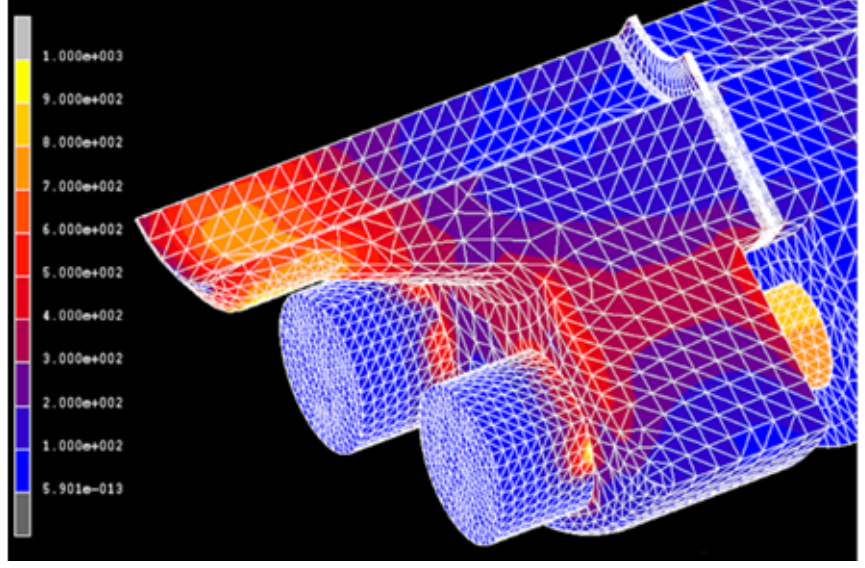

(a)

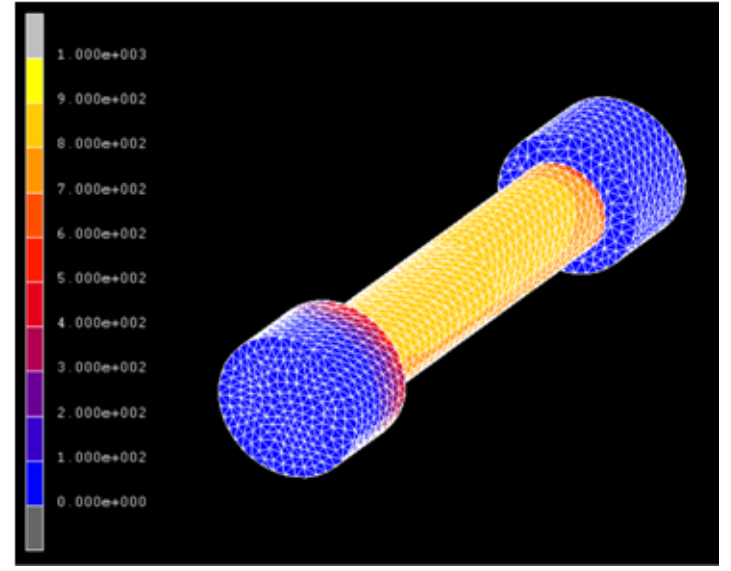

(b)

Figure 5: (a) Stress distribution on the model; (b) equivalent stresses on the pivot.

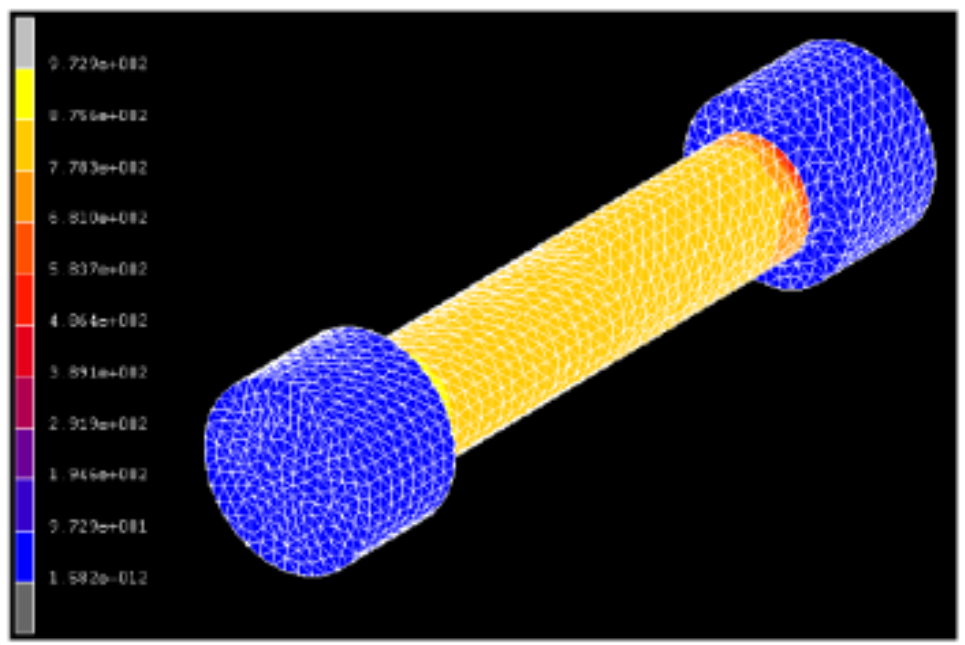

Figure 6: Equivalent stress on the pivot. 


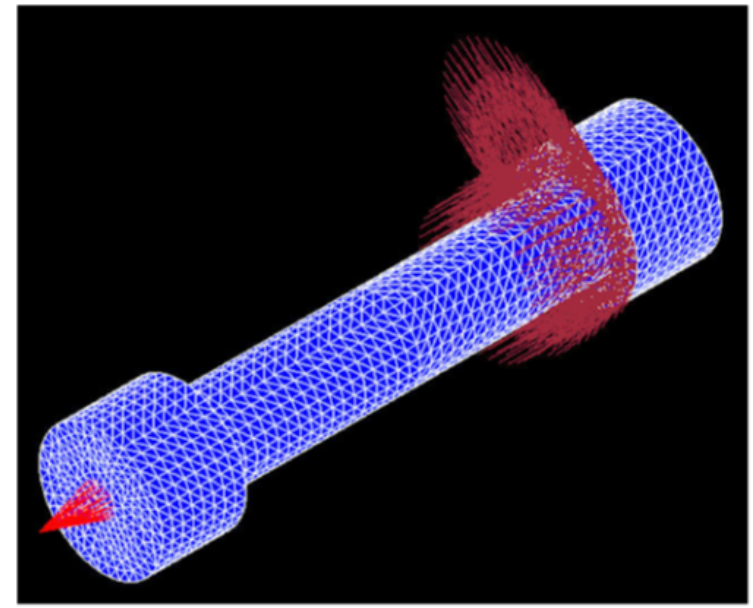

Figure 7: Heat load on the pivot.

In Tab. 4 it has been reported the characteristics of the material used for the simulation during the temperature variation.

\begin{tabular}{ccc}
\hline Temperature $\left[{ }^{\circ} \mathrm{C}\right]$ & Young Module $[\mathrm{MPa}]$ & $\begin{array}{c}\text { Coefficient of } \\
\text { Thermal Expansion }\end{array}$ \\
20 & 210000 & 10.0 \\
100 & 205000 & 11.1 \\
200 & 195000 & 12.1 \\
300 & 185000 & 12.9 \\
400 & 175000 & 13.5 \\
500 & 165000 & 13.9 \\
600 & 155000 & 14.1 \\
\hline
\end{tabular}

Table 4: Characteristics of the material used for the simulation during the temperature variation.

The Fig. 8 shows the pivot stresses distribution in the middle section caused by the temperature.

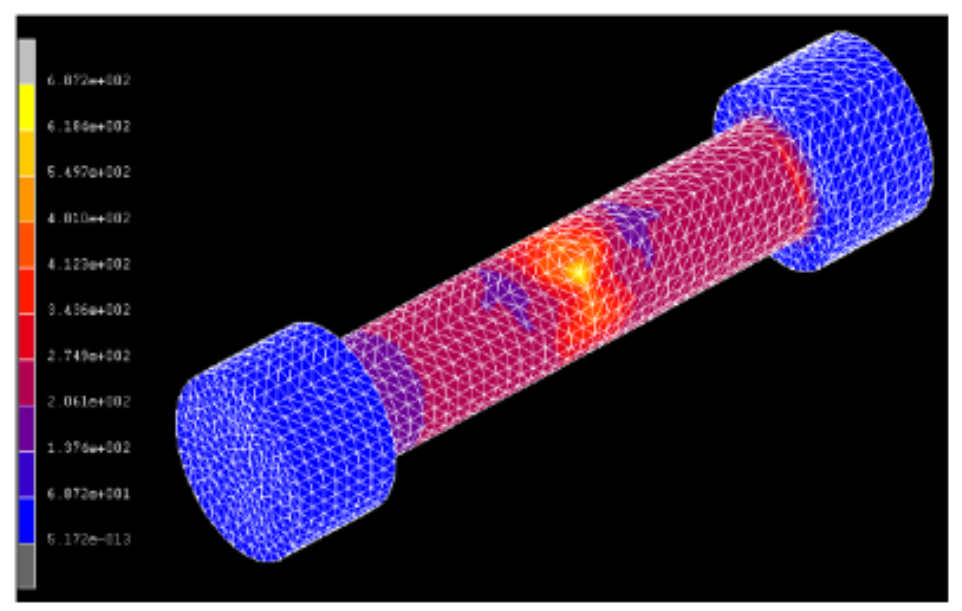

Figure 8: Stress distribution on the pivot caused by the temperature. 


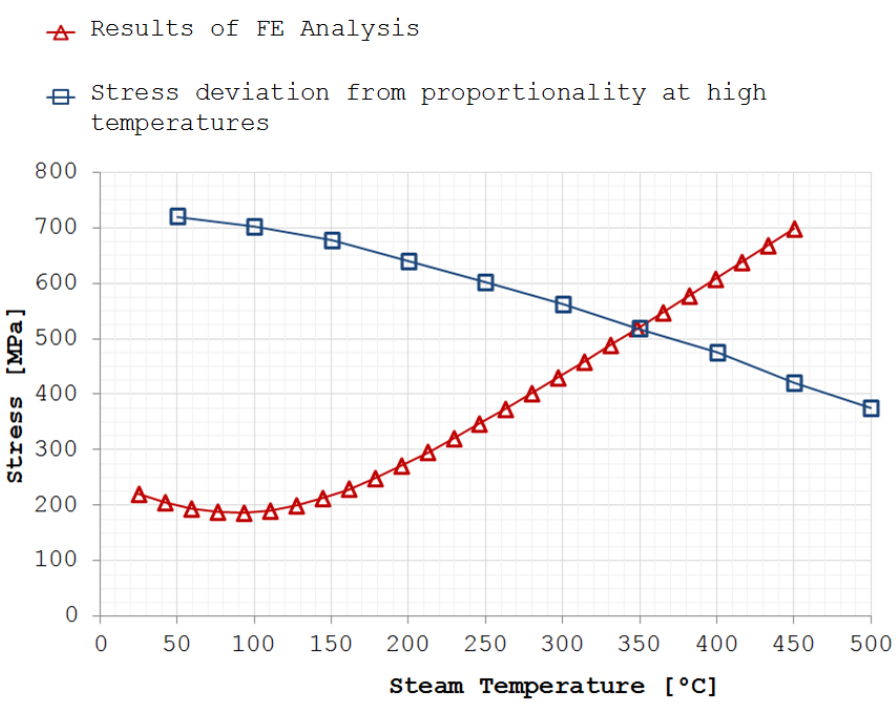

Figure 9: Results of FE Analysis.

The diagram of the Fig. 9 reports the material yield load variation with respect to the steam temperature. In the same graph it has been reported the Von Mises maximum stress value reached in the middle section of the tie rod changing the local temperature and the stress deviation from proportionality at high temperatures. It can be observed that at a $350{ }^{\circ} \mathrm{C}$ temperature the stress value is equal to the material yield stress and with a temperature of $450{ }^{\circ} \mathrm{C}$ (equal to the steam come out from the flange) the stress is $40 \%$ over the material yield stress.

\section{Experimental Analysis}

In order to determine the mechanical characteristics of the material both static and fatigue tests have been performed. As it has been already said, the static tests have been carried out on 2 of the eight specimens, one belonging to the tie rod A (specimen 1) and another of the tie rod B (specimen 2). The tests have been done using an electrohydraulic machine INSTRON ${ }^{(\mathrm{R})} 8501$ with a fixed crossrate equal to $1 \mathrm{~mm} / \mathrm{min}$.

The test has been accompanied by the detection and the acquisition of the surface temperature of the specimens using an IR camera FLIR(R) 3000 with a frame rate of $1 \mathrm{~Hz}$. The Fig. 10 reports the deformation stress graph of one of the tested specimen 1. In the same figure it has been reported the temperature trend of the hottest area of the specimen surface showing the unit deformation of the specimen itself. The temperature trend has been deduced examining the following images obtained during the traction test. For a better understanding, in Fig. 11 it has been reported the first part of the temperature curve vs strain (till $\varepsilon=0.04$ ) of specimen 1 .

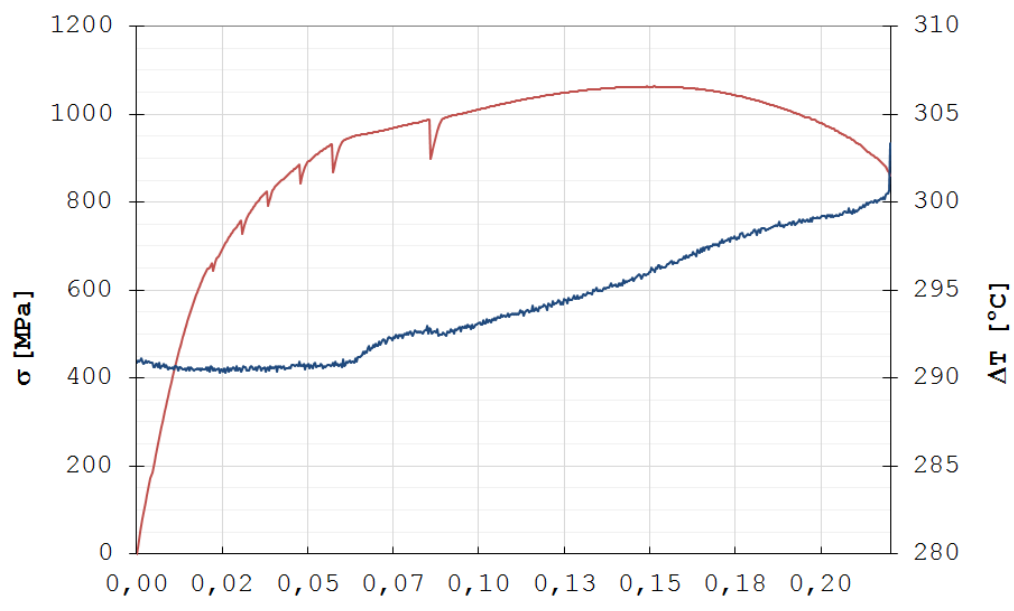

$\varepsilon[8]$

Figure 10: Stress vs strain curve and temperature trend of specimen 1 mono axial static test. 


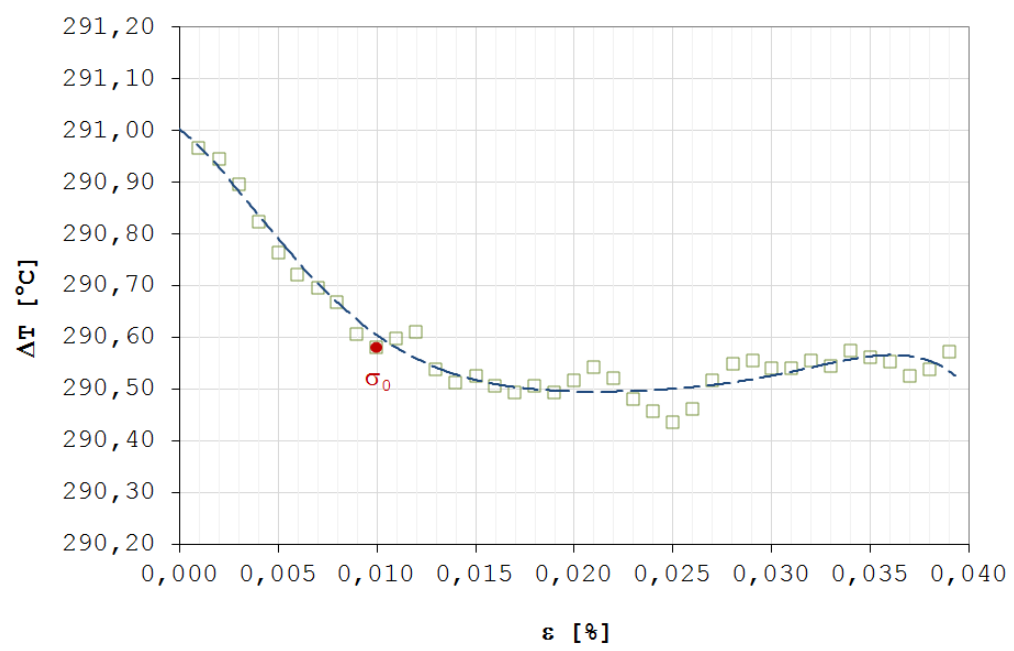

Figure 11: Thermal Map for the specimen 1.

Using the method mentioned before the results of the tests and of the acquisitions done for the specimen 2 are reported respectively in Fig. 12 and 13.

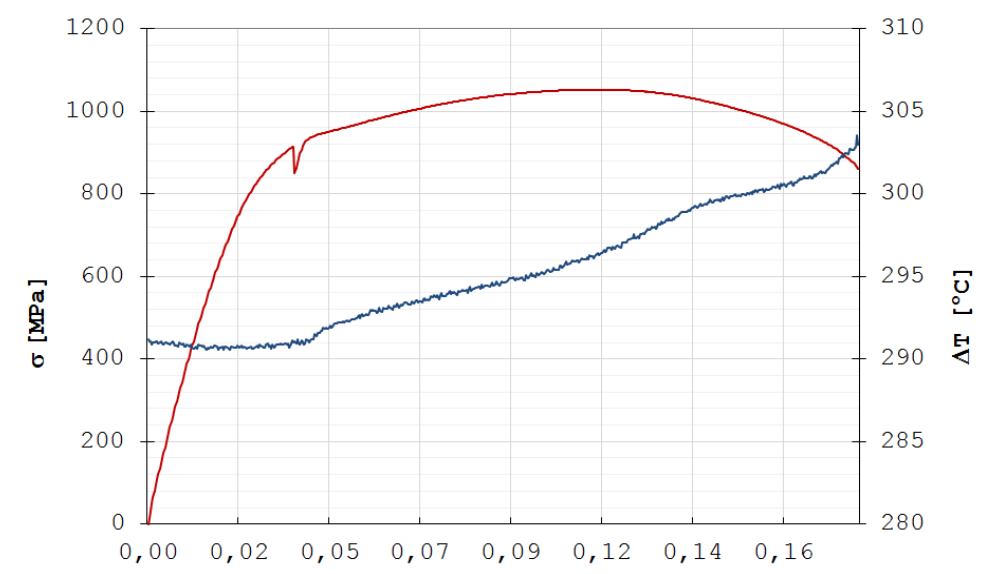

$\varepsilon[8]$

Figure 12: Stress vs strain curve and temperature trend of specimen 2 mono axial static test.

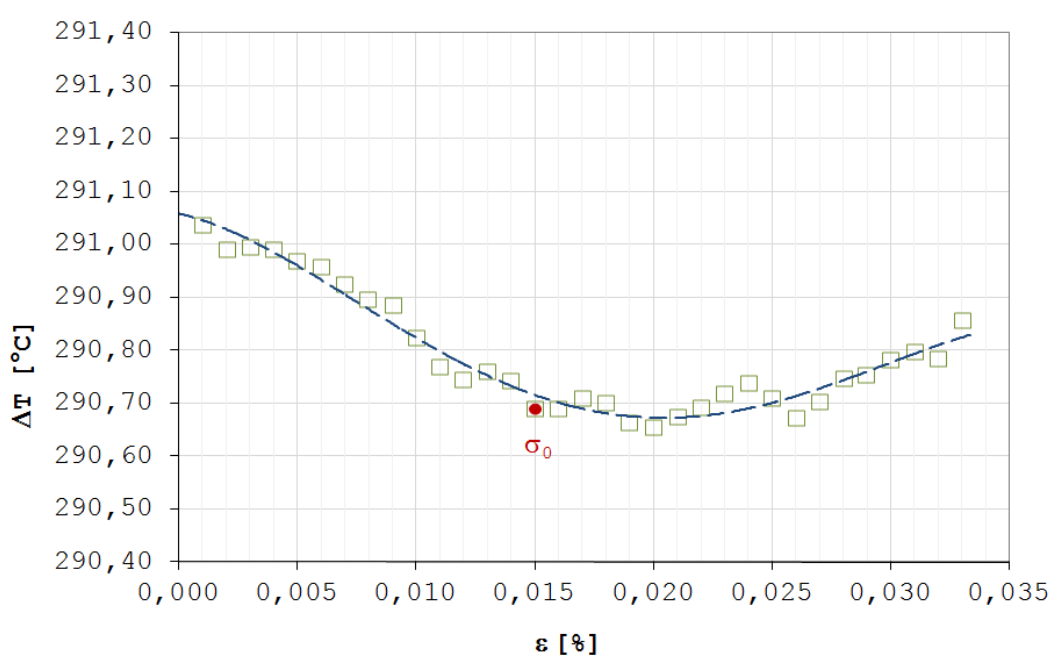

Figure 13: Thermal Map for the specimen 2. 
The Fig. 11 and 13 allow to point out the surface with a perfect thermoelastic behaviour and where the proportionality between the stress(strain) and temperatures count. After putting on strain the testing machine with the clearance recovery, in fact, it has been noticed in both figures a decreasing linear segment for which it is validthe thermoelasticity law with the costant temperature decreases (a perfect segment) up to spot a slope change for the value $\varepsilon=0.010$ in Fig. 11 and $\varepsilon=$ 0.015 in Fig. 13. These values are far from 0.02 which conventionally correspond to the yield stress of the material. The Tab. 5 and 6 resume the results obtained during the static tests in agreement with [15-19]. In the tables with the caption "material without damage" it has been identified the resistance values provided by the tie rods building firm.

\begin{tabular}{lcc}
\hline & Yield Load & $\begin{array}{c}\text { Breaking } \\
\text { Loand }\end{array}$ \\
& $\mathrm{R}_{\mathrm{p} 02}[\mathrm{MPa}]$ & $\mathrm{R}_{\mathrm{m}}[\mathrm{MPa}]$ \\
\hline $\begin{array}{l}\text { Material without damage } \\
\text { Specimen } 1 \text { of an old tie }\end{array}$ & 835 & 1080 \\
$\begin{array}{l}\text { Specimen } 2 \text { of an old tie } \\
\text { rod }\end{array}$ & 859 & 1063 \\
\hline
\end{tabular}

Table 5: Results of Static Test.

\begin{tabular}{lc}
\hline & $\begin{array}{c}\text { Fatigue limit with alternated } \\
\text { symmetric solicitation, } \sigma_{0}[\mathrm{MPa}]\end{array}$ \\
\hline Material without damage & 450 \\
\hline Specimen 1 of an old tie rod & 392 \\
\hline Specimen 2 of an old tie rod & 420 \\
\hline
\end{tabular}

Table 6: Results using the [15-19] theory.

The fatigue tests have been done using the remaining specimens. In particular the first two of them - one belonging to the tie rod 1 and the other belonging to the tie rod 2 - have been used to define an appropriate test protocol (Tab.7) compatible with the values discovered during the static tests. The other 4 (specimen 3 , specimen 4 ) of the tie rod A and of the tie $\operatorname{rod} \mathrm{B}$, have been used following the procedure of Risitano's Rapid Method (RRM) to define the thermal maps [45]: it means the determination of the energy parameters (temperature vs cycles, with parameterized applied load) necessary for the following valuation of the fatigue limit and the contouring of the entire fatigue curve (Wöhler curve). The tests have been done with almost pulsating load (loading ratio $R=0,1$ ) coherently with the on-stream tie rods loading mode. Fig. 14 shows each specimen load history.

\begin{tabular}{ccc|ccc}
\hline $\begin{array}{l}\mathrm{R} \text { (load } \\
\text { ratio) }[/]\end{array}$ & $\begin{array}{c}\text { Starting value (first } \\
\text { step) }[\mathrm{kN}]\end{array}$ & $\begin{array}{c}\Delta \mathrm{P} \text { (gap between the } \\
\text { following steps) }[\mathrm{kN}]\end{array}$ & $\begin{array}{c}\text { Test frequency } \\
{[\mathrm{Hz}]}\end{array}$ & $\begin{array}{c}\text { Cycles for loading } \\
\text { steps [Cycles] }\end{array}$ & $\begin{array}{c}\text { Thermal } \\
\text { images } \\
\text { acquisition }[\mathrm{Hz}]\end{array}$ \\
\hline 0,1 & 36 & 2 & 10 & 10000 & $1 / 25$ \\
\hline
\end{tabular}

Table 7: Fatigue Test Protocol. 


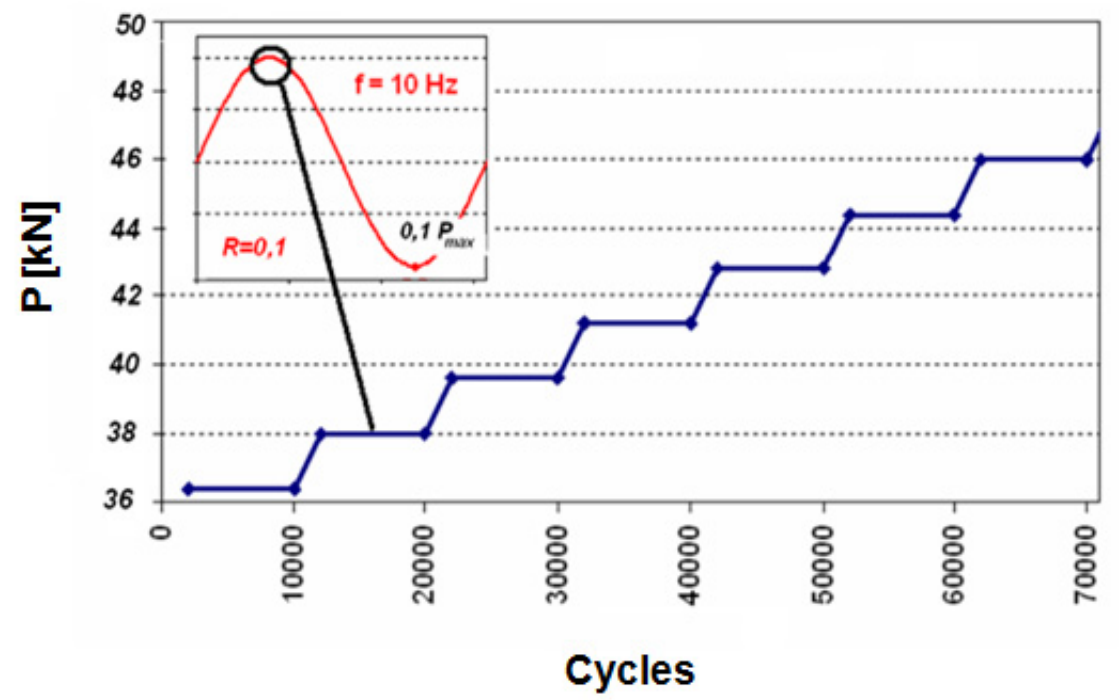

Figure 14: Load history imposed during fatigue test.

After having synchronized both the loading application of the testing machine and the images acquisition, the acquisition rate of IR Camera has been fixed to $25 \mathrm{~s}$ in order to obtain for each load step of $10000 \mathrm{cycles}$ at $10 \mathrm{~Hz}, 40 \mathrm{images}$ to be analyzed. Using this procedure it has been obtained during the analysis phase, the specimen temperature every 250 cycles of load application. The following analysis has been done reconstructing the temperature trend of the warmest area of the specimen surface at the different steps in order to have the temperature diagrams as a function of the cycles (curves parameterized according to the applied load).

From the Fig. 15 to the 18 one it has been reported the thermal maps following the warmest point of the specimen surface revealed during the test. As above mentioned, the temperature data allow to obtain the fatigue limit and the energy parameter $\Phi$.

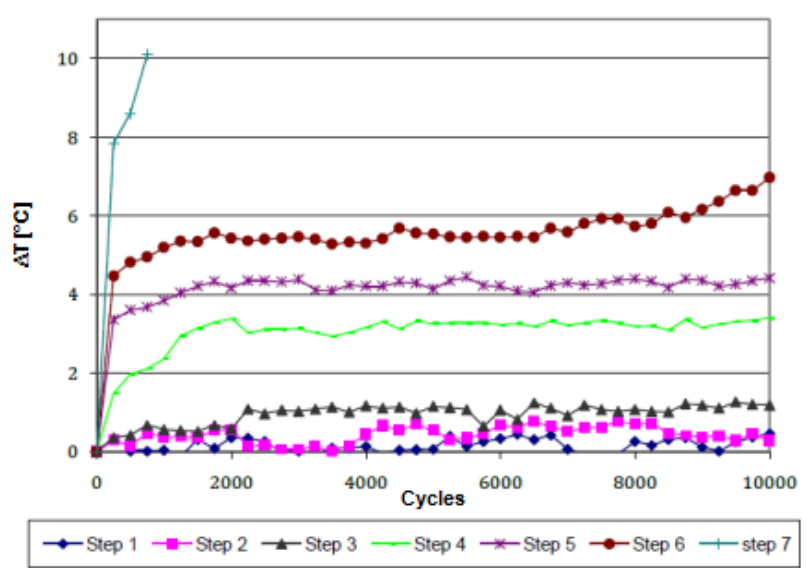

Figure 15: Thermal map of the specimen 3.

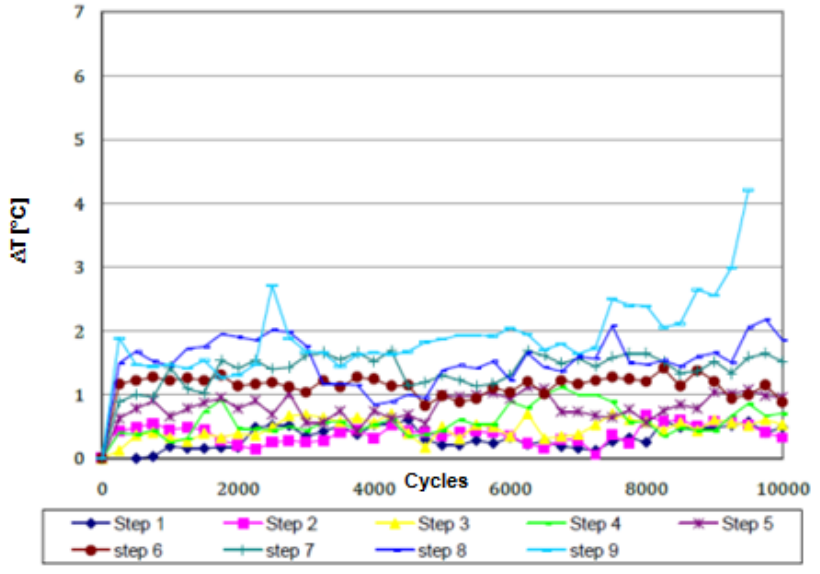

Figure 16: Thermal map of the specimen 4.

Examining the thermal maps and proceeding as indicated in [4-5] it has been obtained the fatigue limit values, the value of the parameter $\Phi$ and therefore the Wöhler curve. It has to remind that the fatigue limit can be estimated directly from the thermal maps (temperature curves) because, being the stress value the same, there aren't irreversible deformations yet and the temperature variation of the specimen surface is zero in all the points. So, for example, for the specimen 1 the fatigue limit is quite below the first applied load level (36 kN / $480 \mathrm{MPa}$ ) (Fig. 15). The Tab. 8 reports the data related with the two specimen categories. 


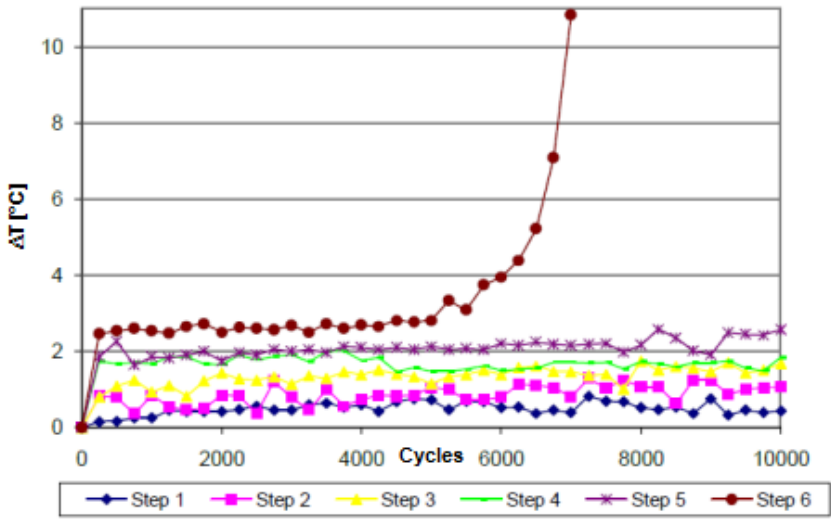

Figure 17: Thermal map of the specimen 5.

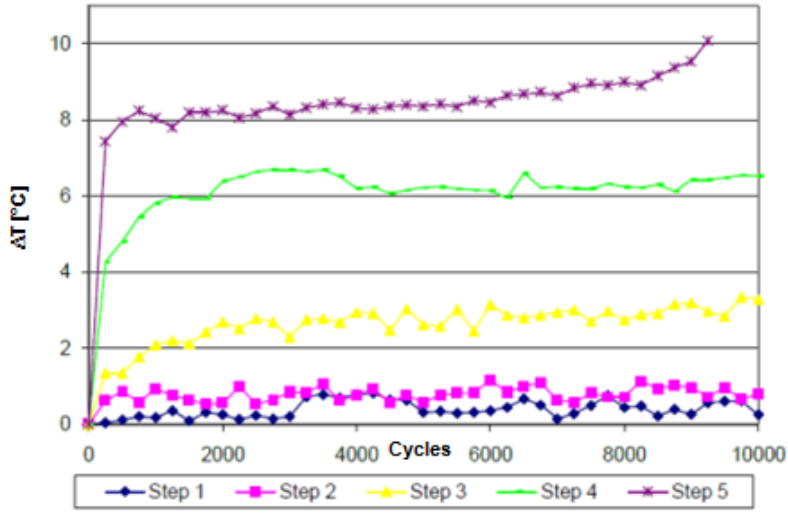

Figure 18: Thermal map of the specimen 6.

\begin{tabular}{lcc}
\hline & Fatigue Limit $\sigma_{0}[\mathrm{MPa}]$ & $\Phi\left[{ }^{\circ} \mathrm{C}\right.$ x Cycles $]$ \\
\hline Specimen type 3 & 475 & $1.44 \mathrm{E}+05$ \\
Specimen type 4 & 460 & $8.70 \mathrm{E}+04$ \\
Specimen type 5 & 445 & $8.13 \mathrm{E}+04$ \\
Specimen type 6 & 440 & $1.85 \mathrm{E}+05$ \\
\hline
\end{tabular}

Table 8: Results data of fatigue test.

Using different colours, in Fig.19 it has been reported the Wöhler curves of each specimen (3, 4, 5, 6). Following as it is indicated in [4-5], the number of the breaking cycles $N_{r}$ for a specific load has been obtained as the ratio between the energy parameter $\Phi$ and the stabilization temperature (the mean value of the detected ones).

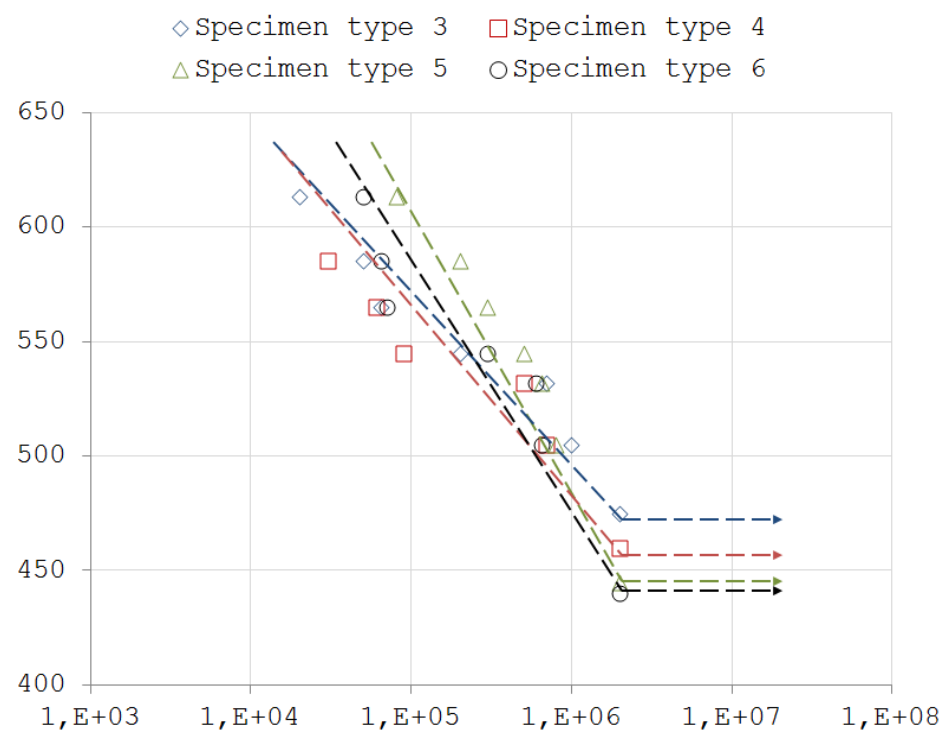

Figure 19: Wöhler curves of each specimen in according with RRM [4-5]. 


\section{DISCUSSION}

he analysis of the results of the numerical simulations have pointed out that the tie rods failure is not due to the exercise or to the assembling conditions but to the bad performance of the flange seal: when it has broken, in fact, it has allowed that two of the tie rods were hit by a steam jet of $450{ }^{\circ} \mathrm{C}$ and a pressure of 160 ATA. It has caused a mechanical effect associated with a decay of the material resistance characteristics, quite shearing. The stress values, calculated during the simulation and which consider the steam jet effect, were above the $40 \%$ of the material yield limit at that temperature. These values suggested a breakage due to the overcoming of the material resistance characteristics. The quite suddenly breakage (without the plastic deformation) led one to suppose a further decay of the material characteristics due to the high temperature at which it has been subjected in a very limited area.

The experimental tests have confirmed the hypothesis of breakage due to the mechanical action of the steam on the tie rod and to the thermal action on the material.

The exam of the results of the static tests show a quite different behaviour for both of the specimen under the static traction. The Tab. 5 shows a small difference of the breaking and yield loads for the two specimen and which is confirmed by the assessment of the symmetrical stress fatigue limit carried out by the temperature curve of Fig. 11 and 13 (392 MPa for the specimen 1 and $420 \mathrm{MPa}$ for the specimen 2)

The results of the fatigue curve confirm the trend already noticed through the static analysis. Both the values of the fatigue limit and the Wohler curves are different for the specimen obtained by the broken bolt A ( 3 and 4 ) and the broken bolt B (5 and 6). Being bolts made of the same material, the cause of their different behaviour is due to the different stress conditions history. Considering the kind of work and the way they have been assembled with controlled draught parameters (use of the torque wrench), it can be justified just with a thermal stress different from the steam loss of the packing flange seal. Considering also the characteristics of the same steam it has probably caused structural changes. It can be deduced both from the thermal maps of each specimen and from the resulting fatigue curves for the two specimens (from tie rod A and from tie rod B), in couples completely different.

\section{CONCLUSIONS}

$\mathrm{I}$ $\mathrm{n}$ the past the static and dynamic analysis examining the thermal release of the stressed material has been adopted to value the failure causes of the mechanical components.

In this work it has been conducted a numerical and experimental study to point out the causes which had determined the failure of the tie rods of a measurement flange, for which, during the maintenance two of the eight tie rods sheared in the mean area where the tensions should be lower. The numerical simulation showed as the breakage cause the high steam coming from the irregular seal pressure-tight. The experimental tests have shown a little decay of the material characteristics.

Considering the limited number of the specimens at our disposal for each type of component (flange tie rods), the analysis has been done detecting the temperatures of the stressed specimens surface. The following analysis of the thermal images which have been collected using a sensor (thermograph at thermal infrared) allowed to point out the characteristics of static and dynamic resistance of the specimens obtained by the two broken bolts.

The results of the static tests with the analysis of the superficial temperature and of the fatigue tests according to RRM (based on energy dissipation in heat) have pointed out a different behaviour of the bolts obtained from the two tie rods.

This result helped to confirm that the only cause for the failure of the two bolts was the seal behaviour which has allowed that the two bolts were abnormally thermally stressed modifying the resistance characteristics of the bolts steel.

The energy study has shown again the opportunity to assess possible damages of the mechanical components. This kind of study, allowing the fatigue characterization through a limited number of specimen, helps to pick out the damage causes necessary for the management and for the future changes and maintenance choices.

\section{REFERENCES}

[1] Geraci, A., La Rosa, G., Risitano., A, L’infrarosso termico nelle applicazioni meccaniche. ATA Ingegneria Automotoristica, 38 (1985) 8-9. 
[2] Curti, G., La Rosa, G., Orlando, M., Risitano, A., Analisi tramite infrarosso termico della "temperatura limite" in prove di fatica, In: Proceedings XIV Convegno Nazionale AIAS, (1986)211-220.

[3] Curti, G., Geraci, A., Risitano, A., Un nuovo metodo per la determinazione rapida del limite di fatica. ATA IngegneriaAutomotoristica, 10 (1989) 634-636.

[4] La Rosa, G., Risitano, A., Thermographic methodology for rapid determination of the fatigue limit of materials and mechanical components. Int. J. Fatigue, 22 (2000) 65-73.

[5] Fargione, G., Geraci, A., La Rosa, G., Risitano, A., Rapid determination of the fatigue curve by the thermographic method. Int. J. Fatigue, 24 (2002) 11-19.

[6] Atzori, B., Meneghetti, G., Energy dissipation in low cycle fatigue of austempered ductile irons, In: Proceedings $5^{\text {th }}$ international conference on low cycle fatigue, (2003)147-152.

[7] Curà, F., Curti, G., Sesana, R., A new iteration method for the thermographic determination of fatigue limit in steels. Int J Fatigue, 27 (2005) 453-459.

[8] Plekhov, O.A., Palin-luc, T., Saintier, N., Uvarov S.V., Naimark O., Fatigue crack initiation and growth in a 35CrMo4 steel investigated by infrared thermography. Fatigue Fract. Eng. Mater. Struct., 28 (2005) 169-178.

[9] Meneghetti, G., Analysis of the fatigue strength of a stainless steel based on the energy dissipation. Int. J. Fatigue, 29 (2007)81-94.

[10] Plekhov O.A., Saintier N., Palin-luc T., Uranov, S.V., Naimark, O., Theoretical analysis, infrared and structural investigations of energy dissipation in metals under cyclic loading. Mater. Sci. Eng., 462 (2007)367-369.

[11] Amiri, M., Khonsari, M.M., Rapid determination of fatigue failure based on temperature evolution: fully reversed bending load. Int J Fatigue, 32 (2010) 382-389.

[12] Crupi, V., Chiofalo, G., Guglielmino, E., Using Infrared Thermography in Low-Cycle Fatigue Studies of Welded Joints. Welding Journal, 89 (2010) 195-200.

[13] Crupi, V., Chiofalo, G., Guglielmino, E., Infrared investigations for the analysis of low cycle fatigue processes in carbon steels. Journal of Mechanical Engineering Science, In: Proceedings of the Institution of Mechanical Engineers Part C, 225 (2011) 833-842.

[14] Clienti, C., La Rosa, G., Risitano, A., D’Andrea, R., Proposta di utilizzo di metodologie termografiche per il controllo di qualità di componenti meccanici. Frattura ed Integrità Strutturale, 12 (2010) 37-47.

[15] Risitano, A., Risitano, G., L’importanza del "parametro energetico" temperatura per la caratterizzazione dinamica dei materiali. Frattura ed Integrità Strutturale, 9 (2009) 123-124.

[16] Clienti, C., Fargione, G., La Rosa, G., Risitano, A., Risitano, G., A First Approach to the Analysis of Fatigue Parameters by Thermal Variations in Static Tests on Plastics. Engineering Fracture Mechanics, 77 (2010) $2158-2167$.

[17] Risitano, A., Clienti, C., Risitano, G., Determination of fatigue limit by mono-axial tensile specimens using thermal analysis. Key Engineering Materials 452-453 (2011) 361-364.

[18] Risitano, G., Clienti, C., Experimental study to verify the fatigue limit found by thermal analysis of specimen surface in mono axial traction test. Key Engineering Materials, 488-489 (2012) 795-798.

[19] Risitano, A., Risitano, G., Determining Fatigue Limits with Thermal Analysis of Static Traction Tests. Fatigue \& Fracture of Engineering Materials \& Structures, 36 (2013) 631-639.

[20] Risitano, A., Risitano, G., Analisi termica per la valutazione del comportamento a fatica di provini soggetti a successive serie di carichi. Frattura ed Integrità Strutturale, 12 (2010) 88-99.

[21] Risitano, A., Risitano, G., Cumulate damage evaluation of steel using infrared thermography.Theoretical and Applied Fracture Mechanics, 54 (2010) 82-90.

[22] Risitano, A., Risitano, G., Corallo, D., Cumulative Damage by Miner's Rule and by Energetic Analysis. SDHM: Structural Durability \& Health Monitoring, 8 (2012) 91-109.

[23] Risitano, A., Risitano, G., Cumulative Damage Evaluation in Multiple Cycle Fatigue Tests Taking Into Account Energy Parameters. Int. J. Fatigue, 48 (2013) 214-222.

[24] Atzori, B., Meneghetti, G., Ricotta, M., Fatigue behaviour of a stainless steel based on energy measurements. Key Engineering Materials, 417-418 (2010) 333-336.

[25] Naderi, M., Amiri, M., Khonsari, M.M., On the thermodynamic entropy of fatigue fracture, In: Proc R Soc A, 466 (2010) 423-438. 